\title{
Pyrite in mud sediments of the East \\ China Sea inner shelf controlled by local environmental variability
}

\author{
XITING LIU ${ }^{1}$, DAVID A. FIKE ${ }^{2}$, ANCHUN LI ${ }^{3}$ AND \\ HOUJIE WANG ${ }^{1}$
}

${ }^{1}$ Ocean University of China

${ }^{2}$ Washington University in St Louis

${ }^{3}$ Institute of Oceanology, CAS

Presenting Author: liuxiting@ouc.edu.cn

Authigenic pyrite is the most common reduced sulfide in marine sediments. Its physical and chemical characteristics have often been used to indicate ocean chemical conditions and related biogeochemical processes. However, recent studies have shown that changes in the local depositional environment could also modulate its content and sulfur isotope composition, and the related mechanisms need to be further confirmed. Different types of mud areas are developed in the marginal seas of eastern China (Bohai Sea, Yellow River, East China Sea), where abundant pyrite is precipitated in the sediments, providing a natural laboratory for studying the control process of pyrite by the sedimentary environment. Our previous studies on the inner shelf of the East China Sea indicate that the sulfur isotope of authigenic pyrite is related to the sedimentation rate, which may be related to the openness of the diagenetic system [1], or related to the anaerobic oxidation of methane (AOM) [2]. The ratio of organic carbon to pyrite sulfur $(\mathrm{C} / \mathrm{S})$ could serve as an important indicator for the evolution of the depositional environment of the East China Sea inner shelf. The C/S ratio of core EC2005 decreased from more than 10 before 13.1 ka to about 1 around 11 $\mathrm{ka}$, indicating the transition from the terrestrial to the marine environment caused by a sea-level rise during the last deglacial period. In the future, we will expand the research area to explore the constraints that different types of organic matter and terrigenous components (such as iron speciation) have on the abundance and isotopic composition of sedimentary pyrite.

References:

[1] Liu, X.T., Li, A.C., Fike, D.A, et al., 2020. Marine Geology, 429: 106307.

[2] Liu, X.T., Fike, D.A, Li, A.C., et al., 2019. Chemical Geology, 505: 66-75. 